\title{
Assessing alternative futures for agriculture in Iowa, U.S.A.
}

\author{
M.V. Santelmann ${ }^{1, *}$, D. White ${ }^{2,3}$, K. Freemark ${ }^{4}$, J.I. Nassauer ${ }^{5}$, J.M. Eilers ${ }^{6,7}$, K.B. Vaché ${ }^{8}$, \\ B.J. Danielson ${ }^{9}$, R.C. Corry ${ }^{10,11}$, M.E. Clark ${ }^{12,13}$, S. Polasky ${ }^{14}$, R.M. Cruse ${ }^{15}$, J. Sifneos ${ }^{1}$, \\ H. Rustigian ${ }^{1}$, C. Coiner ${ }^{16}$, J. Wu $^{16}$ and D. Debinski ${ }^{9}$ \\ ${ }^{1}$ Department of Geosciences, Oregon State University, Corvallis, OR 97331; ${ }^{2}$ Department of Geosciences, \\ Oregon State University; ${ }^{3}$ Current address: U.S. Environmental Protection Agency, Corvallis, OR 97333, USA; \\ ${ }^{4}$ National Wildlife Research Centre, Canadian Wildlife Service, Ottawa, Ontario, K1A 0H3, USA; ${ }^{5}$ School of \\ Natural Resources and the Environment, University of Michigan, Ann Arbor, MI 48109, USA; ${ }^{6} E \& S$ \\ Environmental Chemistry, Corvallis OR; ${ }^{7}$ Current address: MaxDepth Aquatics, Inc., Bend OR 97701, USA; \\ ${ }^{8}$ Department of Bioresource Engineering, Oregon State University, Corvallis, OR 97331, USA; ${ }^{9}$ Department of \\ Ecology, Evolution, and Organismal Biology, Iowa State University, Ames, IA 50011, USA; ${ }^{10}$ School of \\ Natural Resources and the Environment, University of Michigan, Ann Arbor, MI 48109; ${ }^{11}$ Current address: \\ Department of Environmental Design \& Rural Development, University of Guelph, Guelph, Ontario, Canada \\ NIG 2WI, USA; ${ }^{12}$ Department of Ecology, Evolution, and Organismal Biology, Iowa State University, Ames, \\ IA 50011; ${ }^{13}$ Current address: Department of Biological Sciences, North Dakota State University, Fargo, ND \\ 58105, USA; ${ }^{14}$ Departments of Applied Economics and Ecology, Evolution and Behavior, University of \\ Minnesota, St. Paul-Minneapolis, MN 55108, USA; ${ }^{15}$ Department of Agronomy, Iowa State University, Ames, \\ IA 50011, USA; ${ }^{16}$ Department of Agricultural and Resource Economics, Oregon State University, Corvallis, \\ OR 97331, USA; *Author for correspondence (email: santelmm@onid.orst.edu)
}

Received 17 June 2002; accepted in revised form 15 October 2003

Key words: Agriculture, Biodiversity, Socio-economics, Scenarios, Water quality

\begin{abstract}
The contributions of current agricultural practices to environmental degradation and the social problems facing agricultural regions are well known. However, landscape-scale alternatives to current trends have not been fully explored nor their potential impacts quantified. To address this research need, our interdisciplinary team designed three alternative future scenarios for two watersheds in Iowa, USA, and used spatially-explicit models to evaluate the potential consequences of changes in farmland management. This paper summarizes and integrates the results of this interdisciplinary research project into an assessment of the designed alternatives intended to improve our understanding of landscape ecology in agricultural ecosystems and to inform agricultural policy. Scenario futures were digitized into a Geographic Information System (GIS), visualized with maps and simulated images, and evaluated for multiple endpoints to assess impacts of land use change on water quality, social and economic goals, and native flora and fauna. The Biodiversity scenario, targeting restoration of indigenous biodiversity, ranked higher than the current landscape for all endpoints (biodiversity, water quality, farmer preference, and profitability). The Biodiversity scenario ranked higher than the Production scenario (which focused on profitable agricultural production) in all endpoints but profitability, for which the two scenarios scored similarly, and also ranked higher than the Water Quality scenario in all endpoints except water quality. The Water Quality scenario, which targeted improvement in water quality, ranked highest of all landscapes in potential water quality and higher than the current landscape and the Production scenario in all but profitability. Our results indicate that innovative agricultural practices targeting environmental improvements may be acceptable to farmers and could substantially reduce the environmental impacts of agriculture in this region.
\end{abstract}




\section{Introduction}

Humans now dominate many of earth's ecosystems, often with devastating impacts on global biodiversity and biogeochemical cycles (Puckett 1994; Alexander et al. 1996; Vitousek et al. 1997a; Vitousek et al. 1997b; Sala et al. 2000). Of particular concern is agriculture, whose impact on the earth is unparalleled by any other land use in its combination of spatial extent and intensity of influence (Matson et al. 1997). Whereas some envision "A Geography of Hope" for private agricultural lands (USDA-NRCS 1996), others see the potential for "a second Silent Spring" (Krebs et al. 1999).

Agriculture has had an enormous environmental impact on the U.S. Corn Belt region. The U.S. Office of Technology Assessment has designated it as the nation's first priority problem region with respect to surface water quality (US OTA 1995). Three states in this region (Indiana, Illinois, and Iowa) rank 48, 49 and 50 in the amount of natural vegetation remaining out of the 50 states in the U.S. (Klopatek et al. 1979). Over $70 \%$ of the total land base of Iowa is devoted to row crops such as corn (maize) and soybeans, the highest percentage of any state in the U.S. (US Census Bureau 2001). Increasing numbers of livestock are being raised in confined animal feeding operations, reducing pasture land (Freemark and Smith 1995; US GAO 1999). Native flora and fauna have been in decline for decades (Farrar 1981). Equally dramatic are the socioeconomic impacts of current trends in agriculture. If trends of the past 25 years continue, in the next 25 years, many Iowa farmers who now own their land will lose or sell it (USDANASS 1999; Freemark 1995). Farm size will increase as will the land area in large corporate farms operated by employees. Rural landscapes will be depopulated and rural communities will see major changes in demography.

Here, we summarize results of a project to envision futures for agricultural landscapes that offer alternatives to current conditions and trends (Santelmann et al. 2001; Nassauer et al. 2002). We maintained multiple goals in the design and evaluation of these innovative future landscapes. We also introduced dramatic changes in agricultural land use and management, in order to improve water quality and restore native biodiversity, maintain agricultural enterprises and economic return to farmers. We worked to design landscapes that would also be acceptable to people who live and visit there. We asked not only, "What might these landscapes be like in 25 years with continued priority given to corn and soybean production?" (the Production scenario), but also, "what should and could they be like?" if among our goals for agricultural watersheds are streams with clean water, natural areas with diverse vegetation, abundant wildlife, and attractive rural landscapes populated by farmers working their own land (e.g., the Water Quality and Biodiversity Scenarios). Our hypothesized social drivers were varying levels of priority given to agricultural production, water quality, and maintenance and restoration of native biodiversity in public values, support and policy. Nassauer et al. (2002) describe the alternative futures in detail. Here, we focus on the interdisciplinary evaluation and assessment of these alternative futures. Our objective is to compare the potential for these alternatives to achieve multiple goals by summarizing and integrating the quantitative impacts of landscape change embodied in the scenario futures for multiple endpoints, ranging from economic and social metrics to modeled estimates of native biodiversity and water quality. We also compare evaluative approaches used in this project, employing a framework based on Levins (1966) paper that could assist other interdisciplinary projects in thinking about the advantages and limitations of various evaluative methods.

These scenarios were not intended to be prescriptions of what to do on specific parcels of land. Rather, they were intended to inform and inspire decisionmakers to look beyond the existing landscape and envision greater possibilities for agriculture (Nassauer and Corry 2004; Peterson et al. 2003). The scenarios were designed to allow the exploration of multiple impacts of recommended strategies for addressing environmental problems associated with agriculture using spatially-specific models and computer-simulated images of the resulting landscapes. This interdisciplinary assessment of the alternative futures integrates the results from disciplinary teams that evaluated the social, economic, and environmental impacts that may result from making changes that have been recommended to address agricultural and environmental problems. Methods used by the disciplinary teams are outlined briefly here. More detailed description of methods used in modeling and evaluation of the futures may be found in other publications from the project (Coiner et al. 2001; Vaché et al. 2002; Rustigian et al. 2003). 


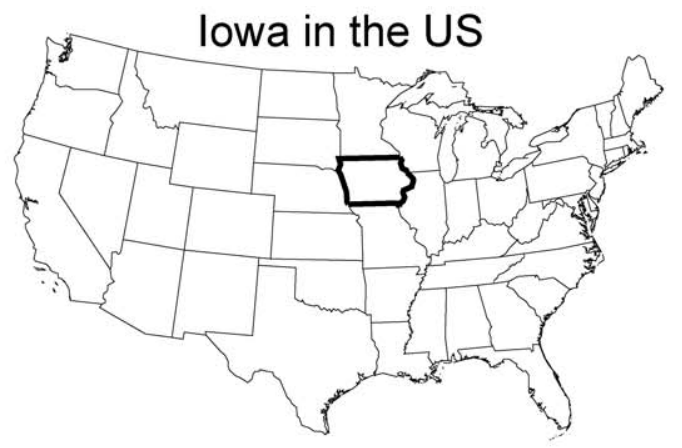

\section{County Study Area in lowa}

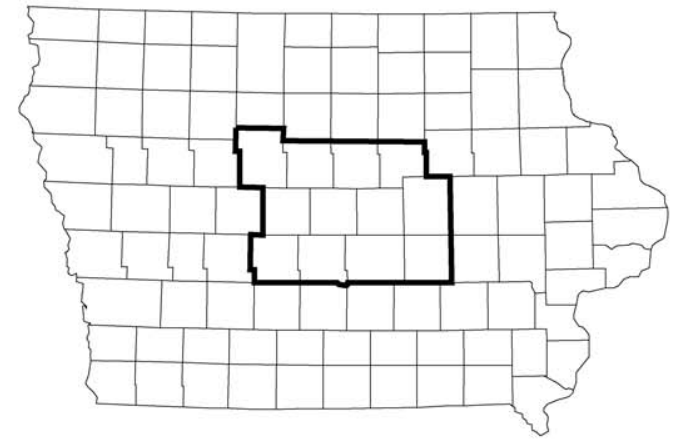

\section{Study Watersheds in 12 County Area}

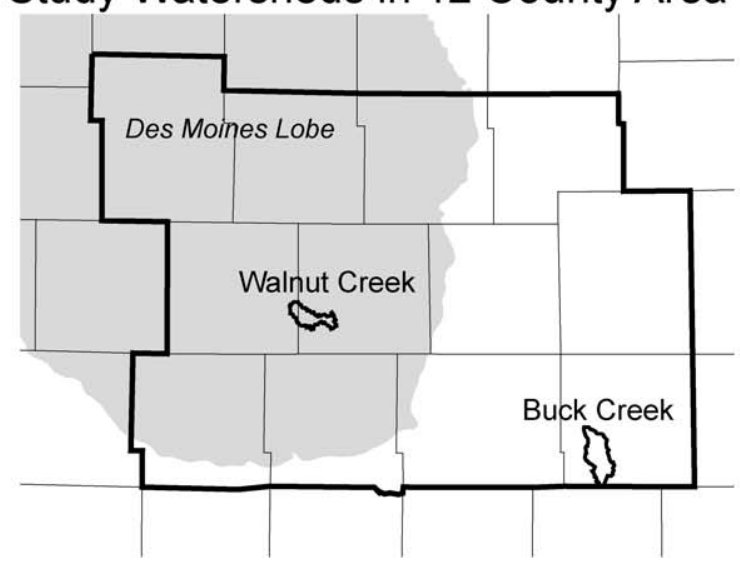

Figure 1. Location of Iowa in the U.S.A. and of the study watersheds in Iowa.

\section{Methods}

Study area

The two watersheds chosen for this study, Walnut Creek (5130 ha) and Buck Creek (8820 ha), are located in Iowa, in the heart of the U.S. Corn Belt (Fig- ure 1). These watersheds were selected to illustrate the way each scenario might be implemented in different physiographic regions, with different sets of agricultural enterprises. Walnut Creek is located in Boone and Story Counties southwest of Ames, Iowa in the Des Moines Lobe physiographic region of Iowa (Prior 1991). The Des Moines Lobe region is characterized by relatively low topographic relief and rich prairie soils. Once a mosaic of prairie and prairie pothole wetlands, now more than $80 \%$ of the land area in the region has been converted to row crops, primarily corn and soybeans. Buck Creek, in Poweshiek County, is located on the Southern Iowa Drift Plain, an older, more dissected landscape with much more topographic relief, highly erodible soils, greater amounts of land currently in pasture, forest, and the Conservation Reserve Program, and only $45 \%$ of the land area in row crops (Freemark and Smith 1995). Land use and land cover for both watersheds were digitized into a GIS at $3 \mathrm{~m}$ resolution under the US EPA Midwest Agrichemical Surface and Subsurface Transport and Effects Research (MASTER) program from aerial photographs taken in 1990 (1:20,000) and extensively ground-truthed in 1993 and 1994.

\section{Scenario futures design}

Landscape futures for the three scenarios (Nassauer and Corry 1999; Nassauer et al. 2002) were designed by a team of landscape architects using an iterative process (Nassauer and Corry 2004). The process engaged disciplinary experts in agronomy, plant and animal ecology, wetlands ecology, water quality, hydrology, agricultural policy, agricultural extension, and GIS, including regional experts as well as project collaborators. The futures are not simply digital maps of land cover in two Iowa watersheds; they represent the plausible outcomes on the landscape of very different human priorities for agricultural lands. They are not predictions of the future, but are rather an example of what could happen if normative principles were used to achieve societal goals of improvements in water quality, restoration of biodiversity, and economically healthy rural communities. In their 2001 article, Mitsch et al. make specific recommendations for practices needed to reduce nutrient loading in the Upper Mississippi River Basin, including:

- wetland restoration

- riparian buffers

- changes in cropping and fertilization 
- manure management

Many of these practices (as well as those recommended by USDA-NRCS 1996) are elements of our future scenarios, but here they are made spatially specific in the context of existing watersheds, allowing the use of spatial models for landscape-level quantification of multiple impacts, including comparison of economic, social and environmental outcomes. We chose to use watersheds of this size because land management decisions are often made at the spatial scale of these watersheds, and because research and decision-making at both smaller and larger scales could be informed by investigation of responses to land management at this scale.

In the Production scenario (Figure 2, Figure 3), profitable agricultural production is assumed to be the dominant objective of landscape management. This scenario therefore assumes that policy encourages cultivation of all highly productive land with the use of fossil fuels, chemicals, and technology to a degree similar to the present. It assumes public support for large-scale, high-input agriculture, and trust in the safety and quality of food produced. Corn and soybean row crops are extended to all areas of highly productive soils. Best management practices (BMPs) targeting protection of water quality and biodiversity typical of the region under the 1996 Federal Agricultural Improvement and Reform Act (Public Law 104127 [H.R. 2854] April 04, 1996) are assumed to be comprehensively adopted in 2025. The landscape is depopulated by 50\% compared with 1994. Many farmsteads and woodlots are removed, average farm size doubles, and field size increases up to 130 ha. Livestock are raised almost exclusively in confinement operations in a few counties of the state, but not in the study watersheds.

The Water Quality scenario (Figure 2, Figure 3) assumes that agricultural enterprises change in response to a (hypothetical) new federal policy enforcing clear, measurable water quality performance standards for surface and groundwater, and supporting agricultural enterprises that efficiently reduce soil erosion, reduce sediment delivery to streams, minimize transport of excess nutrients to streams, reduce the rapid hydrologic response to storm events, and improve aquatic habitat. Forage crops and rotational grazing (carefully managed to minimize impacts on riparian systems) are widely adopted as profitable enterprises supported by federal policy to help meet water quality performance standards on erodible land. Conventional BMPs (minimum tillage, rotations, strip cropping, continuous cover, and animal agriculture) are employed. Wider stream buffers of native vegetation and new, innovative BMPs detain and clean stormwater. Woodlands are retained for carefully-managed grazing. Both urban and rural citizens appreciate the pastoral appearance of agricultural landscapes. Farm vacations and countryside second homes bring urban people into rural areas. To manage livestock operations and respond to rural recreation demand, $50 \%$ more farmers live in these agricultural landscapes in 2025 than under the Production scenario.

The Biodiversity scenario (Figure 2, Figure 3) assumes that technology and agricultural practices respond to a (hypothetical) new federal policy to increase the abundance and diversity of native plants and animals in the context of agriculture. Public investment creates a comprehensive system of indigenous species bioreserves of at least 260 ha (640 acres), connected by a network of wide habitat corridors that also buffer streams. Federal support encourages adoption of innovative, biodiversity best management practices (e.g., perennial strip intercropping and agro-forestry) in a biodiversity target zone to further connect and buffer the new bioreserves. Beyond this target zone, corn and soybeans are grown on soils that are highly suitable for cultivation. Livestock enterprises continue to trend toward confinement operations, constructed to meet rigorous standards for sewage treatment, in a few counties of the state, but not in the study watersheds. Public investment in reserves and corridors invites public enjoyment of the rural landscape. Trail systems connect the corridor system and reserves. While farm size increases and the number of farms decreases as in the Production scenario, nearly all farmsteads present in 1994 remain inhabited. Many non-farmers who enjoy rural landscapes live on farmsteads formerly occupied by farmers.

The resulting alternative futures are landscape mosaics characterized by changes in field size, cropping and tillage practices, perennial cover within fields (e.g., grassed waterways, filter strips, field skips) and conversion of cropland to rotational pasture or hay (Figure 2, Figure 3). The futures also differ in the occurrence and spatial extent of non-crop habitats interspersed among fields (e.g., fencerows, riparian buffers of differing widths, woodland, prairie, and wetland reserves). The alternative futures and the decision making rules used to generate them are described in 
Present and Future

Scenarios

for Walnut Creek

Watershed
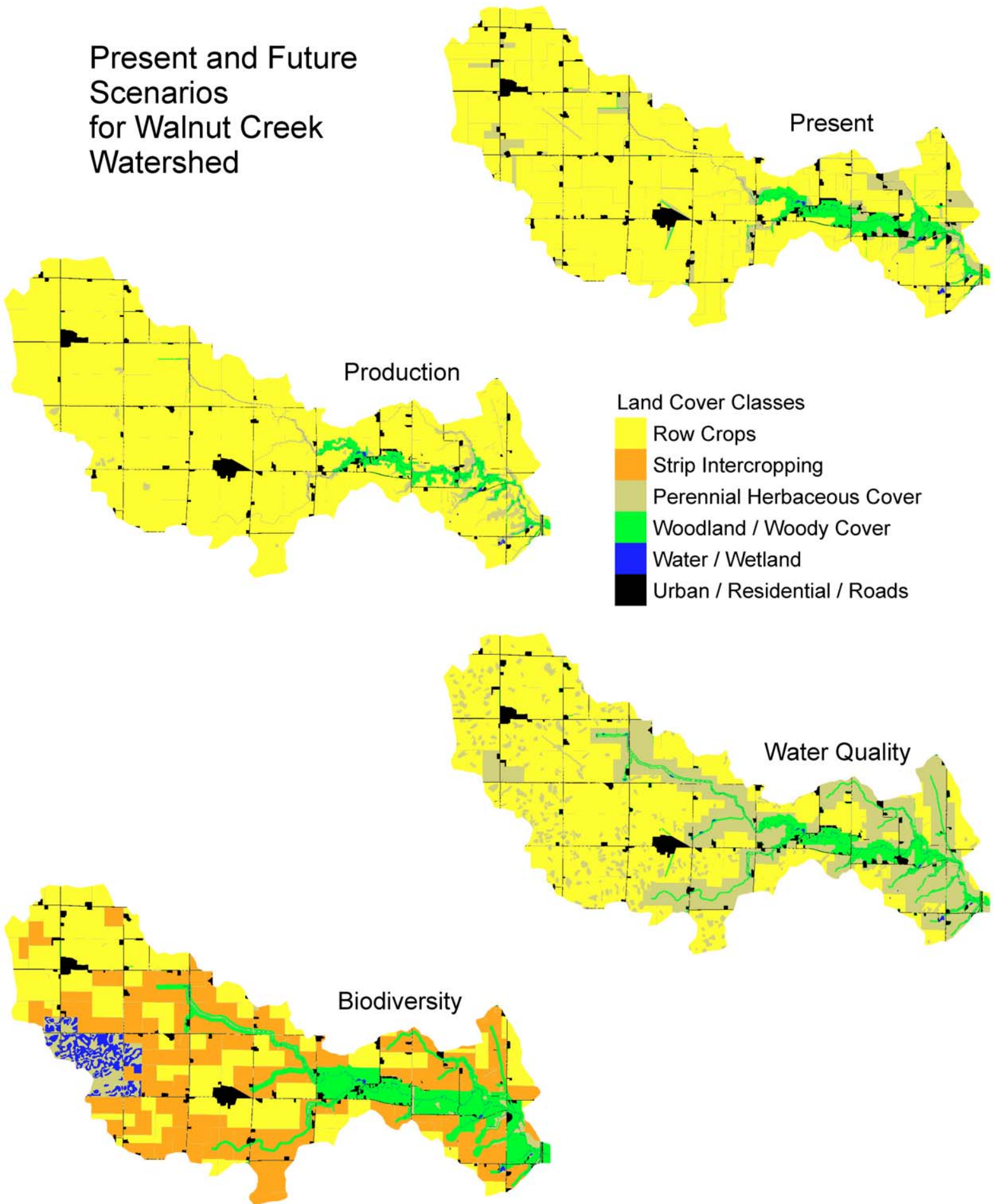

Figure 2. Present landscape (top right) and designed alternative future scenarios for Walnut Creek watershed. Note the increase in land area in row crops at the expense of perennial cover for the Production scenario; the increased amount of land in perennial cover (pasture and forage crops) as well as wider riparian buffers in the Water Quality scenario; and the strip intercropping, wide riparian buffers and extensive prairie, forest and wetland restorations in the Biodiversity scenario. 


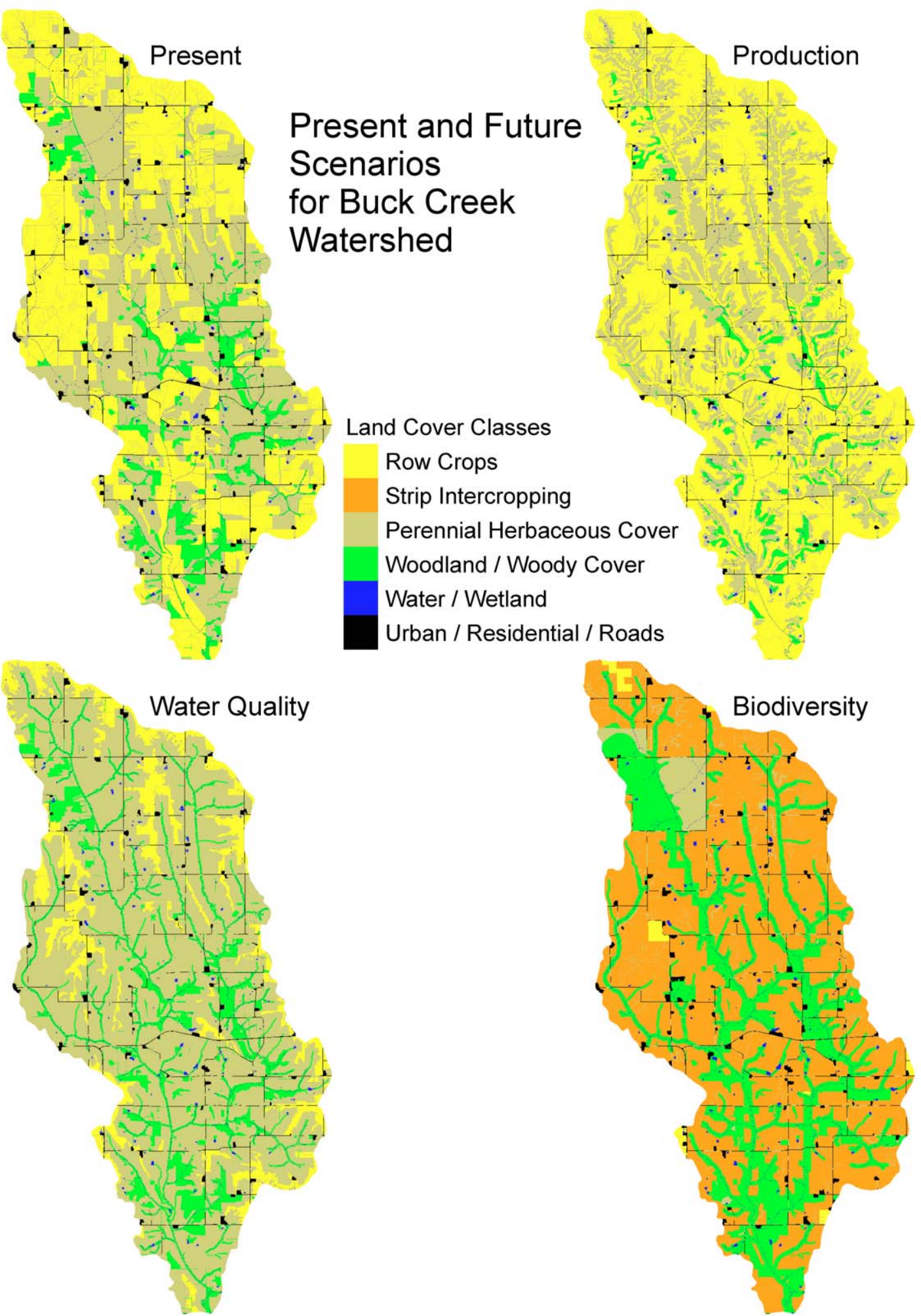

Figure 3. Present landscape (top left) and designed alternative future scenarios for Buck Creek watershed. Note scenario features similar to those for Walnut Creek but applied to a different landscape (e.g., the physiography of the watersheds led to the design of forest, savanna, and upland prairie reserves in Buck Creek rather than the riparian forest and prairie/ prairie pothole wetlands which comprised the reserves in Walnut Creek watershed). 
more detail in Nassauer and Corry (1999). Vaché et al. (2002) also provide a table that lists the area (in hectares) of all major land cover types in each scenario for both watersheds, and shows the percent change in area relative to current landscape.

\section{Scenario futures evaluation}

The alternative futures were compared to one another and to the current condition of these watersheds using GIS-based models and digital simulations of the alternative landscapes. Changes in land use and management in the alternative futures were evaluated for their impacts on water quality (discharge, export of total suspended sediment (TSS) and of nitrate), estimated economic return, farmer preference, and impacts on native plants and animals (habitat-area based estimates of plant, butterfly, and vertebrate species diversity; spatially-explicit population modeling for mammal and amphibian species). For our purposes, native plant species were defined as those designated as native to Iowa in the USDA PLANTS database (USDA-NRCS 1997), and native animal species were defined as those designated by The Nature Conservancy's Natural Heritage Program as native to Iowa. More detailed methods are given for each evaluative approach in the project publications cited below.

The water quality model SWAT (Soil and Water Assessment Tool (Arnold et al. 1997)) was used to evaluate scenarios for water quality response (Vaché et al. 2002). Water quality data used to calibrate SWAT have been collected on Walnut Creek for 11 years as part of the USDA Management Systems Evaluation and Assessment program (Hatfield et al. 1999). Water quality and hydrologic monitoring stations were established on Buck Creek and data were collected during 1997 and 1998 for model calibration in that watershed (Shoup 1999).

For evaluation of the economic impacts of the alternative futures, the EPIC model (Erosion Productivity Index Calculator (Williams et al. 1988)) was used to calculate crop yields. Crop enterprise budgets from The Iowa State University Extension Service were used to calculate production costs. Price data from 1987 to 1997 from the National Agricultural Statistics Service, indexed to 1998 , were used to calculate an average price for conventional crops (e.g., maize, soybeans, oats, alfalfa). Information on crop yields and prices were combined to estimate revenue, from which we subtracted cost to generate estimates of farmer profit or "return-to-land" (Coiner et al. 2001). The EPIC model also generates estimates of externalities such as soil erosion and nitrate losses to runoff and leaching from the rooting zone.

We developed a spatially explicit, content-specific method for determining a landscape preference rating for alternative future scenarios (Nassauer and Corry 1999). Thirty-two farmers sorted 20 images of landscape features drawn from the three scenarios into preference classes, identifying landscapes that were "best for the people of Iowa in 25 years." A mean preference score was calculated for each image, with higher scores indicating higher preference. Each landcover class was assigned a preference rating based on the mean ratings of the images of that landcover. A landscape preference rating was calculated for each scenario using the product of the mean preference scores of land cover types depicted in representative images for the scenario and the area in that land cover. A structured interview format was used to elicit in-depth information about the perceptions of each farmer rather than to measure perceptions of a representative sample of a larger population (Nassauer and Corry unpublished data). Structured interviews included a Q-sort (1-5 scale normally distributed) forced-answer component in which farmers rated landscapes on their desirability for the future of the people of Iowa. To include farmers who worked in both rolling and flat landscapes, with different crop and enterprise mixes, we sought to interview similar numbers of farmers in Poweshiek County $(n=15)$, who were more likely to grow hay, and in Story County $(n=17)$, who were more likely to grow corn and soybeans. In each county, we interviewed farmers of fewer than 80 acres, farmers of more than 640 acres, and several farmers of between 80 and 640 acres. Mean farm size is 360 acres for each county; median farm size is 210 acres for Poweshiek County and 180 acres for Story County. We also targeted some farmers who had demonstrated their ability to innovate with landcover; about half of interview participants had land currently or previously enrolled in the Conservation Reserve Program.

For evaluating risk to biodiversity, we used two types of methods. First, we used a statistical estimate of change in habitat area, weighted by habitat quality (White et al. 1997), for all butterfly and non-fish vertebrate species that occur in central Iowa, or by estimated abundance in that habitat (Eilers and Roosa 1994) for all plant species that occur in central Iowa, in order to have an index of the response to land use 
change for all species in a given taxon across a broad range of taxa (White et al. 1999). This method is both feasible for large numbers of species, and straightforward in its assumptions that habitat area and habitat quality are important influences on species diversity. These assumptions are consistent with the findings of recent articles and reviews that indicate the importance of both habitat area and habitat quality in influencing species diversity (Rosenzweig 1997; Dupré and Ehrlen 2002) and population density (Bender et al. 1998). Second, we used spatially explicit population models (SEPMs) to assess the impact of changes in land use and management on species of interest (Dunning et al. 1995), and to compare the results of these spatially-explicit, process-based modeling approaches to the habitat-area based method. The SEPMs were used to estimate and compare relative densities for all mammal species occurring in central Iowa in the alternative futures after 100-year model runs (Clark and Danielson unpublished data) and abundance of breeding females and species persistence through 100-year model runs for four selected amphibian species (Rustigian 1999; Rustigian et al. 2003).

\section{Integration of results}

Each disciplinary research team on the project has prepared and published articles that present in greater detail the methods used in their evaluation of the futures (Coiner et al. 2001; Nassauer et al. 2002; Vaché et al. 2002; Rustigian et al. 2003) and discuss their results from a disciplinary perspective. Here, we focus on describing the methods used to summarize and compare the results of all the evaluative models for each scenario across disciplines.

One challenge in summarizing the results of an interdisciplinary project is deciding how to compare "apples and oranges"; e.g., changes in profitability or farmer preference with changes in water quality or biodiversity. In some cases, the choice might be to convert all impacts into a common currency, e.g., dollars, and produce a single number or rank for a given scenario. We chose not to do so here, for multiple reasons, among them the desire to retain as much information as possible for stakeholders to use in making their own decisions.

In order to present results of multiple endpoints on a common scale for comparison, we expressed each endpoint in terms of percent change relative to current conditions (difference between future and present value of the endpoint divided by the present value) such that positive change reflected improvement in conditions relative to goals of the scenarios. We considered the following changes as improvements: greater profit, greater area in land use selected by farmers as "better for the state of Iowa", increase in land cover with relatively high native plant density or high suitability for native animal species, increase in estimated potential abundance of native species, decrease in export of nitrate and total suspended sediment, and a decrease in annual discharge. When more than one entity was being used to constitute the indicator (such as a set of plant or animal species for biodiversity), we used the median of the individual percent changes.

Each scenario in Walnut Creek (Figure 4a) and Buck Creek (Figure 4b) was evaluated for ten indicator endpoints (see below), for which percent change was calculated as above.

Water quality response, endpoints 1-3:

1) annual discharge in $\mathrm{m}^{3} /$ year

2) annual export of sediment in tonnes/year

3) annual export of nitrate-nitrogen in $\mathrm{kg} / \mathrm{year}$

All three endpoints above were estimated using the SWAT model (Vaché et al. 2002).

Economic profitability, endpoint 4:

4) annual return to land (RTL) summed for watershed (U.S. dollars).

This endpoint was estimated using EPIC as described in methods (above) and Coiner et al. (2001). This endpoint does not include any income from federal programs targeting environmental improvements. Such payments would be in addition to profits shown here, which are only from commodities produced.

Farmer perception, endpoint 5:

5) cumulative preference rating for each future, based on farmer rating of images related to each future landcover

This endpoint was calculated from the farmer interviews as described above and in Nassauer and Corry (1999).

\section{Biodiversity response, endpoints 6-10:}

6) index of native plant biodiversity ( median percent change for all native plant species $(n=932)$ of index of abundance in each land cover, weighted by area of that land cover) 

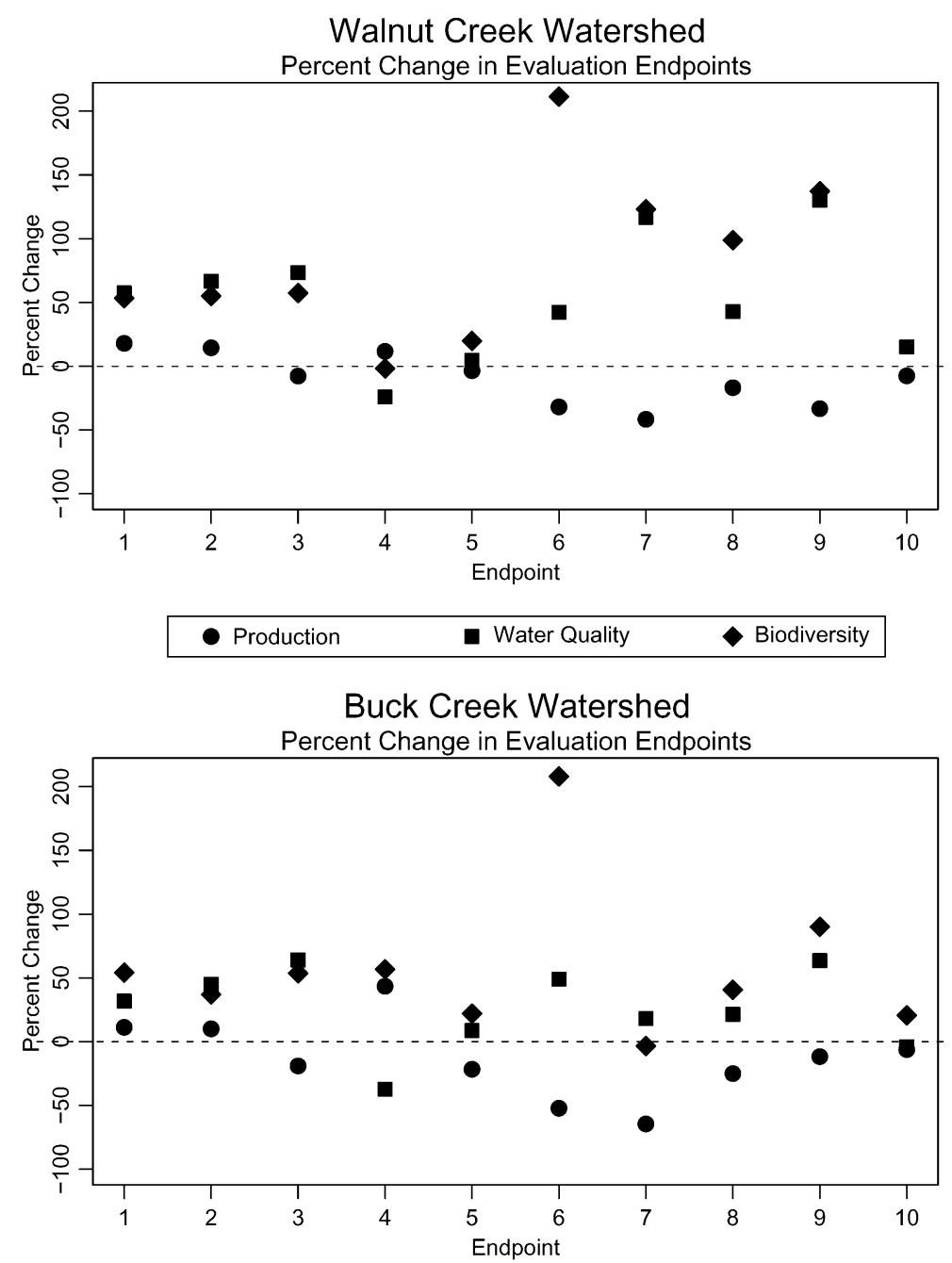

Figure 4. Results of the ten endpoints modeled for Walnut Creek (a) and Buck Creek (b), presented as percent change relative to current landscape. The Biodiversity scenario ranks consistently above the Production scenario in all endpoints, and the Water Quality scenario ranks above the Production scenario in all but economic profitability (endpoint 4). Endpoints of plant and amphibian biodiversity (endpoints 6 and 10) exhibit the greatest change and the greatest differences among scenarios, with the prairie/wetland reserve in the Walnut Creek Biodiversity scenario yielding the greatest improvement relative to the present (the change in amphibian biodiversity for Walnut Creek was $916 \%$, off the regular scale of the figure).

7) index of butterfly biodiversity (median percent change for all butterfly species $(\mathrm{n}=117)$ in habitat area in each land cover weighted by suitability of that land cover for the species)

8) index of native vertebrate biodiversity (median percent change for all bird, mammal, reptile, and amphibian species $(\mathrm{n}=239)$ in habitat area in each land cover weighted by suitability of that land cover for the species)

9) index of response for mammal species (median percent change for all mammal species $(n=50)$ of relative density in simulation year 100 of species per- sisting in the watershed).

10) index of response for four amphibian species (median percent change in mean number of breeding females in simulation year 100).

The methods used to calculate changes in suitability-weighted habitat area for plant and vertebrate species are those described in White et al. (1997). The mammal diversity endpoint is from Clark et al. (unpublished data) and the amphibian endpoint is based on data presented in Rustigian et al. (2003). 


\section{Results}

The results of modeling with SWAT (Vaché et al. 2002) indicated that the changes in land use and management practices envisioned in both the Water Quality and Biodiversity scenarios could lead to substantial improvement in water quality. For example, reductions in annual stream discharge for the Water Quality and Biodiversity scenarios were estimated to be $30 \%$ and $50 \%$, respectively, for Buck Creek, and over $50 \%$ for both scenarios in Walnut Creek (endpoint 1, Figure 4). We interpret the decrease in stream discharge as a positive feature of the scenarios, caused largely by a decrease in storm runoff, thus allowing more water for infiltration and groundwater recharge. However, even the Production scenario showed some improvement relative to the current landscape (about 20\% for Walnut Creek and 10\% for Buck Creek), primarily resulting from the comprehensive adoption of conservation tillage in this scenario.

Export of TSS (endpoint 2, Figure 4) is similar in response to discharge, with the Water Quality and Biodiversity scenarios showing reductions of approximately 50\% in Walnut Creek, and the Production scenario similar to the current landscape. In Buck Creek, reductions in TSS for the Water Quality and Biodiversity scenarios were approximately $40 \%$, with the Production scenario similar to the current landscape.

Nitrate export (endpoint 3, Figure 4) was estimated to show reductions of over $50 \%$ in the Water Quality and Biodiversity scenarios in both watersheds. For the Production scenario, the model estimated a slight increase in nitrate export relative to the current landscape for both watersheds. For comparison, in the current landscapes of Walnut Creek and Buck Creek watersheds, annual discharge estimated by SWAT was $9.5 \times 10^{6}$ and $14 \times 10^{6} \mathrm{~m}^{3} \mathrm{yr}^{-1}$, respectively; annual export of nitrate was estimated at $63.4 \times 10^{3}$ and 54.4 $\times 10^{3} \mathrm{~kg} \mathrm{yr}^{-1}$, respectively, and annual export of sediment was estimated to be 532 and 1673 tonnes $\mathrm{yr}^{-1}$, respectively.

The Biodiversity scenario scored highly in terms of economic profitability and farmer perception endpoints. Return-to-land (RTL), a measure of total watershed profit generated from agricultural operations, was almost unchanged in Walnut Creek and 30-40\% higher in Buck Creek (endpoint 4, Figure 4) relative to current estimates of total watershed RTL of $\$ 1.55$ and \$1.35 million dollars (U.S.) for Walnut and Buck
Creek, respectively. In Buck Creek, the relatively high RTL in the Biodiversity scenario occurred in part as a result of large areas converted from pasture or set-asides to strip intercropping, estimated to be more profitable. Although in Walnut Creek, the Biodiversity scenario had reduced area in agricultural production, the enterprises were sufficiently profitable to yield RTL similar to those estimated for the current landscape (Coiner et al. 2001).

Results from calculations of preference ratings for each scenario were consistent with farmer interview comments about images. In each watershed, the Biodiversity scenario was most preferred, followed by the Water Quality scenario and the current landscape. The Production scenario was least preferred for both watersheds (endpoint 5, Figure 4). Several images of the Water Quality scenario also ranked quite high in farmer perceptions, and many farmers interviewed showed a preference for the Water Quality scenario, in which more farmers remain in the watershed farming their own land. However, the extensive, pastured livestock operations and the corn/bean/oatalfalfa rotations of the Water Quality scenario were the least profitable agricultural enterprises modeled given recent trends in pricing of agricultural commodities. Thus, of the two scenarios that showed substantial water quality improvements, the Biodiversity scenario performs better than the Water Quality scenario for economic profitability and cultural acceptability (Nassauer and Corry 1999).

As expected, the Biodiversity scenario ranked highest in most endpoints for estimating impact to native biodiversity (Figure 4, endpoints 6-9). Only butterfly diversity in Buck Creek watershed ranked below current values for the Biodiversity scenario, reflecting both conversion of pastureland to strip intercropping in that scenario (which does not result in improved habitat for butterflies) and because the reserves designed for Buck Creek watershed did not include wetland restorations. The soils maps for Buck Creek watershed that were used to assist in scenario design did not show extensive areas of former wetlands in the parts of the watershed where reserves were located, thus, the Buck Creek bioreserves did not include restoration of habitat for species associated with wetlands. In Walnut Creek, where pasture and grassland make up less than $4 \%$ of the current landscape, and where reserves contained extensive prairie, wetland, and forest restorations, native biodiversity endpoints (butterfly, plant, and vertebrate diversity and amphibian abundance), are substantially 
higher in the Biodiversity scenario than in the current landscape or the Production scenario (Figure 4). For terrestrial vertebrate species (endpoint 8, Figure 4) biodiversity is almost double in Walnut Creek in the Biodiversity scenario versus a $17 \%$ decrease in the Production scenario. This overall improvement resulted not only from establishment of biodiversity reserves, a key element for amphibians (Rustigian et al. 2003), but also from changes in cropping and tillage practices. Conversion to alternative crops and the use of innovative agricultural practices modified large areas (e.g., the $83 \%$ of Walnut Creek and $45 \%$ of Buck Creek currently in row crops) that provide little habitat for native plants and animals in the current landscape.

\section{Discussion}

\section{Ranking of future scenarios; implications of model results}

Although the high ranking of the Biodiversity scenario for biodiversity endpoints was expected, an unexpected finding is that land use and management practices of the Biodiversity scenario are estimated to be nearly as profitable as current practices, rank highest in farmer acceptability, and provide water quality improvements similar in magnitude to those estimated for the Water Quality scenario.

Our water quality modeling results add to the growing body of literature indicating that substantial improvement in water quality downstream from agricultural regions will require substantial change in agricultural practices (Schilling and Thompson 2000; Becher et al. 2000). Cropland comprises over $80 \%$ of the land cover in some watersheds in the Corn Belt (Freemark and Smith 1995). Currently-employed BMPs that affect only a small percentage of the landscape are not sufficient to process or remove the nutrients and sediment exported from cropland under conventional agricultural practices. Model results for these watersheds indicate that under the Production scenario, nitrate export increases slightly and suspended sediments decrease slightly. However, under the Water Quality and Biodiversity scenarios, nearly 3-fold decreases in nitrate export and 2-fold decreases in sediment production are estimated. The Water Quality and Biodiversity scenarios are quite similar in predicted water quality (endpoints 1-3, Figure 4), and substantially better than either the Production scenario or the current landscape. Although the Production scenario specifies universal application throughout the watershed of conventional BMPs (universal use of conservation tillage, 3-6 m buffer strips on permanent stream channels, filter strips, and precision farming targeting fertilizer applications to minimize nutrient additions) water quality benefits estimated to occur under the Production scenario are minimal. Continued export of high levels of nutrients and sediment would be expected to continue current trends of degradation in the aquatic systems of agricultural regions and downstream. These findings are consistent with the expert opinions of farmers in the region, expressed in our farmer preference studies, in which farmers identified the Biodiversity scenario, the scenario with biodiversity as the leading policy objective and with novel, challenging land management practices, to be best for the people of Iowa, and an intensification of agricultural production to be least good for the people of Iowa. The Production scenario was least preferred by farmers interviewed and did not perform well with respect to water quality and native biodiversity. Of the three alternatives, the Production scenario scored lowest in terms of farmer preferences, water quality and biodiversity endpoints. Only in profitability did the Production scenario fare well; not surprising, since this scenario emphasized agricultural commodity production. In addition, the proportional improvement in profitability in any scenario was relatively low compared to improvement in other endpoints, suggesting that current practices are near maximum profitability but much improvement is possible for environmental endpoints.

An important caveat to the interpretation of the economic endpoints is that not all economic costs and benefits resulting from changes in land use and management could be incorporated within the scope of this project. Return-to-land only captures profits from the agricultural operation. No attempt was made to estimate the level of payments from federal programs that might be made to encourage adoption of the practices in the scenarios, nor did we attempt to estimate the value of environmental protection or ecosystem services. For example, this endpoint does not include the economic benefit of improved water quality or enhanced native biodiversity, or benefits to society at the national and international scale, such as the benefit of increased soil organic carbon (Robinson et al. 1996) to mitigate global climate change, or the benefit of reduced nitrate export from agricultural watersheds on coastal waters. It does not include eco- 
nomic costs of chronic non-point source pollution and erosion, or costs of environmental disasters resulting from the episodic failure of manure treatment facilities that might be associated with the large confined feeding operations located outside the study watersheds. Incorporation of these costs would tend to decrease the economic profitability of the Production scenario, and enhance the overall profitability of the Water Quality and Biodiversity scenarios. It was beyond the scope of this project to investigate the regional-scale influences and interactions of the changes in agricultural practices suggested in the scenarios on profitability of the agricultural enterprises, however, this could be a topic for subsequent research. The research and rules used to develop the alternative futures described here and elsewhere (Nassauer and Corry 1999) provide a foundation for the investigation of various scenarios for implementation of alternative management practices at a regional scale.

\section{Comparison of evaluative approaches}

All methods for evaluating impacts to biodiversity yielded similar results. The Biodiversity scenario, designed to enhance native biodiversity, accomplished its goal. The Water Quality scenario, with highest priority on water quality improvement also yielded improvements in native biodiversity relative to the present, and the Production scenario was always worse than the existing landscape at maintaining native biodiversity. The absence of wetland restoration in the Buck Creek implementation of the Biodiversity scenario (because the historical records used to inform the reserve designs did not show wetlands in these areas) led to much lower improvements in high quality habitat area for butterflies and in amphibian abundance in that watershed. In Walnut Creek, where a prairie and wetland preserve was part of the design for the Biodiversity scenario, amphibian abundance and butterfly biodiversity were substantially improved in the Biodiversity scenario (improvements of $>900 \%$ and $>100 \%$, respectively).

Although biodiversity endpoints calculated from results of spatially-explicit population modeling of the alternative futures and the habitat-area based methods both yielded the same rankings of the scenarios, the use of SEPMs allows us to develop some hypotheses and directions for further research in biodiversity responses to landscape change. The results of dynamic modeling of mammal communities
(Clark et al. unpublished data) demonstrate the potential for significant effects from species interactions, with direct consequences for land management. For example, increasing grassland patch sizes resulted in reduced densities and diversity of grassland rodents due to competition, with reductions in predators of rodents as a further consequence. These results contrast with other studies (e.g., Blake and Karr 1987) in which increased forest patch size is correlated with greater diversity of bird species, suggesting the need for research on the dynamics of mammal communities in grasslands of agricultural regions.

Most efforts for developing landscape-level management strategies have focused on conservation planning and maintenance of diversity through general theoretical principles on habitat fragmentation, intensive single-species case studies, or static, habitat-based analyses (Pressey et al. 1993; Rabb and Sullivan 1995; Collinge 1996). Comparison of results from different models used in our project as well as from other studies indicates that the effects of both habitat loss and interspecific interactions in future landscapes must be considered. We emphasize, too, that there are advantages for using data on change in habitat area to estimate first-order biodiversity impacts. This method can rapidly indicate potential effects of landscape change on a broad range of species. In addition, such estimates are easy for watershed managers and planners to generate if they can estimate the initial area and change in area for each type of land cover, and have a means (e.g., USFWSGAP 2003) to link species occurrence to land cover.

Contrasts between water quality modeling approaches applied at different scales (the field-based, unit-load approach of the nitrogen component of EPIC and the spatially-distributed, landscape-level water quality model SWAT) illustrate the scaledependency of water-quality results, as well as limitations of field-scale modeling approaches for representing watershed-level processes. Both models ranked the Water Quality scenario as best for decreasing nitrate export in surface runoff, followed closely by the Biodiversity scenario, with nitrate in runoff from the Production scenario more than twice that for the Water Quality scenario, but still an improvement over current practices. However, because EPIC is designed primarily for estimation of yield at the field scale, "externalities" such as nitrate export, are also calculated at the field scale. Thus, nitrogen transformation processes associated with routing of flow through riparian buffers or into wetlands are not 
modeled in EPIC. The SWAT model, which does route flow and models deposition and transformation processes in the landscape (including those areas not involved in agricultural production) is better suited for watershed-level modeling of water quality.

Estimates of nitrate export for Walnut Creek watershed from SWAT were consistently lower than similar estimates from EPIC (here, nitrate export from EPIC modeling is calculated as the sum of nitrate-N runoff and leaching below the rooting zone, assuming that most of the nitrate that leaches below the rooting zone will still be transported to the stream via tile drains). The nitrate-N exports estimated by SWAT from Walnut Creek were $93 \%$, 93\%, 36\%, and 39\% of those estimated by EPIC for the current landscape, the Production scenario, the Water Quality scenario, and the Biodiversity scenario, respectively. The model results are thus most similar in landscapes such as the current or the Production scenario landscape, where minimal land area is dedicated to features such as wetlands, riparian buffers, or preserves that promote nitrogen transformation or uptake/retention in perennial vegetation. Where such features comprise substantial areas of the watershed (e.g., the Water Quality and Biodiversity scenarios), EPIC and SWAT give very different estimates of nitrogen export. The estimates of water erosion from fields produced by EPIC are not comparable to the export of sediment in streams. The EPIC estimates of soil erosion are 25 to 50 times greater than the annual export of sediment in Walnut Creek estimated by SWAT in all scenarios, again underscoring the difference between a field-based model and a watershed-based model in which flow is routed and deposition of sediment can occur. Understanding the implications of landscape change on water quality for entire watersheds requires application of models designed to integrate processes over larger spatial scales rather than models that sum field scale results for the watershed. Regional modeling of the potential consequences of implementing these alternative futures in much larger hydrologic units would be a logical next step.

The economic endpoint used to evaluate the scenarios is very different from the social endpoint in its focus on precise estimation of a subset of the components of the economic profitability of the scenarios (e.g., crop yields) rather than qualitative indicators of the acceptability of the landscape as a whole (e.g., visual preference). The farmer preference studies used to explore the cultural acceptability of the future landscapes to farmers are not intended to be quanti- tatively precise. Rather, these studies were intended to provide an indicator of which scenarios and scenario components Iowa farmers believe are "good for the state of Iowa", and to help identify elements about which there is relatively more or less agreement of opinion. As with all estimates of human attitudes and behavior, the results have a high level of uncertainty. In addition, because attitudes are not necessarily good predictors of behavior (Arcury 1990), these results cannot be extrapolated to predict the probability of implementation of practices in the scenarios. The farmer preference studies could even be viewed as another iteration of the scenario design process, used to solicit the expert opinion of producers in the region.

As the previous examples suggest, an important part of communicating the results of this interdisciplinary project is discussion of the methods used, the degree to which they allow us to answer important questions about the alternatives, and the most appropriate scale at which to apply the results to answer specific questions. Each discipline involved in scenario evaluation has a disciplinary legacy that influences the degree to which the evaluative techniques of that discipline target realism, precision, or generality (Levins 1966). Every project has resource constraints that affect choice of methods. There are tradeoffs between generality, realism, transferability, accuracy and precision in evaluative approaches. Table 1 characterizes the evaluative approaches we used in terms of criteria that might be important to decision makers, both in deciding how much weight to give each endpoint in decision-making and with respect to guiding efforts to improve on or select the most appropriate evaluative approaches for future applications.

For example, because the farmers we interviewed live in the counties in which our watersheds occur, we expect that our results realistically portray the perceptions of local farmers (degree of realism is high), but realize that the generality of these results to larger regions of the Midwest could be low. Policy makers interested in knowing about cultural acceptability of practices in these scenarios across the region might wish to invest in more extensive interviews and surveys to explore the generality of these results across the region. An investigator exploring the use of various approaches or models for estimating economic return in a watershed under various management plans might consider the degree to which the choice of model constrains the types of 





future enterprises that can be accurately evaluated. In our case, the choice of EPIC was based on its utility for estimating corn and soybean yields, which are highly important in the present landscape and Production future, and still important but less so in some of the futures. Thus, the same modeling approach can be more realistic, accurate and precise for some future landscapes than for others. The nature of economic enterprises comprising all futures should be known and considered before the choice of modeling approach is decided.

If improved accuracy in modeling impacts to native biodiversity is important to decision makers, the need to invest in watershed-scale research to be used for calibration and validation of models used to estimate the response of native plants and animals to landscape change should be apparent from Table 1. Allocation of research funds to monitoring and assessment and choice of modeling approach to use may depend on whether it is important to investigators to estimate impacts to all species in the watershed with moderate accuracy and precision, or impacts on one or a few species with a high degree of realism and accuracy.

\section{Beyond ranking of future scenarios for Iowa watersheds}

In addition to producing quantitative comparisons of spatially-specific future scenarios to aid in current decision-making for agricultural watersheds, this project is valuable as an example of successful interdisciplinary research. Presentation and publication of our work has informed and improved subsequent watershed-level conservation and land-use planning efforts and scenario studies (Lamy et al. 2002; Baker et al. in press) and augments the work of others in this developing field (e.g., Peterson et al. 2003; Steinitz et al. 2003; Tress and Tress 2003). The scenarios we designed have explored innovative practices and dramatically different policy alternatives. We have applied fundamental precepts of landscape ecology in novel ways to investigate possible outcomes when the entire agricultural matrix is modified to achieve ecological functions. A major strength of this project has been extensive interdisciplinary collaboration that has fostered design and evaluation of alternatives across a broad spectrum of goals and evaluative techniques in three areas of scenario assessment: cultural, economic, and ecological.
The future scenarios developed here also provide specific components for watershed-level experimental research that is needed for model validation/ evaluation. The lack of long term ecological research sites in agricultural watersheds, in which such experiments could be carried out, is a severe handicap to agro-ecosystem research. Agricultural experiment stations have a different, equally important mission which should not be pre-empted for ecosystem research. To explore the ecological impacts of alternative land use and management strategies at the watershed scale, long term ecological research in agricultural watersheds similar to what has been done in forested ecosystems (e.g., Likens et al. 1977) is needed.

\section{Conclusions}

The design and evaluation of alternative futures can facilitate discussion and collaboration among stakeholders and policy makers, allowing evaluation of economic, social, and ecological costs of alternative priorities for agricultural regions, and visualization of landscapes that could result from those priorities. The approach presented here provides a means to generate and evaluate a broad range of innovative alternatives, identify those that are desirable for multiple endpoints, and to focus both policy and research on promising aspects of those options.

The results presented here indicate that:

1. if current trends toward intensification of agricultural production continue, further degradation in water quality and loss of native biodiversity in agricultural regions will be a likely consequence,

2. substantial improvements in water quality and native biodiversity could be achieved by implementing substantial changes in land use and management practices, if public support and agricultural policy place high priority on clean water and restoration of habitat for native species,

3. these changes can be designed so that they are comparable to current practices in profitability and yield much greater environmental improvements than practices designed solely with economic profit in mind,

4. these changes may be culturally acceptable to farmers and preferred to current trends as long as agricultural enterprises remain profitable, 
5. there is room for substantial improvement relative to current practices in all endpoints used to evaluate landscape response without sacrificing profitability, and

6. there is a need for long term ecological research in agricultural systems to study the watershed-level impacts of changes in land use and management, to validate the models results presented here, and to allow exploration of environmental responses to agricultural practices across scales.

This study is the first in the U.S. to integrate interdisciplinary research on economic profitability, cultural acceptance, water quality, and native biodiversity using a scenario design and evaluation approach for agricultural ecosystems. Using the agricultural landscape itself as the means to integrate the various disciplinary responses to changes in land use and management, we have begun to quantify the socioeconomic and ecological benefits and costs of continuing current practices and to compare these to the benefits and costs of potential change. Although models can only approximate the watershed-level response of various endpoints to changes in land use, they allow us to rank alternatives with respect to their effectiveness in achieving the desired objectives (Starfield 1997). They provide a starting point for further analyses of the scenario elements (such as wetlands, riparian buffers, woodlands, alternative cropping and management practices) that appear to drive changes in the ecological and socioeconomic endpoints. More importantly, they provide a potential framework for watershed-level field experiments for model validation and investigation of the effects of spatial scale in model application, and for quantification of effects of changes in agricultural land use and management (Ahern 1999). Once we can quantify the impacts of such changes, it becomes easier to evaluate the outcomes of different policy choices, and to translate human priorities for healthy agricultural ecosystems into "A Geography of Hope" (USDANRCS 1996).

\section{Acknowledgments}

We thank the US-EPA STAR grants program (Water and Watersheds, grant \#R-825335-01) for funding, those involved with the MASTER program for sharing with us data essential to this project, and all participants in the initial project workshop that laid the groundwork for the scenario designs. We thank the reviewers who helped improve this paper. We extend special thanks to the Iowa farmers who participated in our interviews. This document has been subjected to the Environmental Protection Agency's peer and administrative review and approved for publication.

\section{References}

Ahern J. 1999. Spatial Concepts, Planning Strategies and Future Scenarios: A Framework Method for Integrating Landscape Ecology and Landscape Planning. In: Klopatek J.M. and Gardner R.H. (eds), Landscape Ecological Analysis: Issues and Applications. Springer-Verlag, New York, New York, USA, pp. 175-201.

Alexander R.B., Smith R. and Schwartz G. 1996. The Regional Transport of Point and Nonpoint-Source Nitrogen to the Gulf of Mexico. Proceedings of the Gulf of Mexico Hypoxia Management Conference, December 5-6, 1995, Kenner, Louisiana, U.S. Geological Survey, Reston, Virginia, March 5, 1996.

Arcury T.A. 1990. Environmental Attitude and Environmental Knowledge. Human Organization. 49(4): 300-304.

Arnold J.G., Williams J. and Maidment D.R. 1997. Continuous time water and sediment routing model for large basins. Journal of Hydrologic Engineering 121: 171-183.

Baker J.P., Hulse D.W., Gregory S.V., White D., Van Sickle J., Berger P.A., Dole D. and Schumaker N.H. 2004. Alternative futures for the Willamette River Basin, Oregon. Ecological Applications. In press.

Becher K.D., Schnoebelen D.J. and Ackers K.B. 2000. Nutrients discharged to the Mississippi River from eastern Iowa watersheds. Journal of the American Water Resources Association 36: 161-173.

Bender D. J., Contreras T.A. and Fahrig L. 1998. Habitat loss and population decline: a meta-analysis of the patch-size effect. Ecology 79: 517-533.

Blake J.G. and Karr J.R. 1987. Breeding birds of isolated woodlots: area and habitat relationships. Ecology 68: 1724-1734.

Coiner C., Wu J. and Polasky S. 2001. Economic and environmental implications of alternative landscape designs in the Walnut Creek watershed of Iowa. Ecological Economics 38: 119-139.

Collinge S.K. 1996. Ecological consequences of habitat fragmentation: implications for landscape architecture and planning. Landscape and Urban Planning 36: 59-77.

Dunning J.B., Stewart D.J., Danielson B.J., Noon B.R., Root T.L., Lamberson R.H. and Stevens E.F. 1995. Spatially-explicit population models: current forms and future uses. Ecological Applications 5: 3-11.

Dupré C. and Ehrlen J. 2002. Habitat configuration, species traits and plant distributions. Journal of Ecology 90: 796-805.

Eilers L.J. and Roosa D.M. 1994. The Vascular Plants of Iowa. University of Iowa Press, Iowa City, Iowa, USA.

Farrar D. 1981. Perspectives on Iowa's declining flora and faunaA symposium. Proceedings of the Iowa Academy of Science 88: $1-6$.

Freemark K. 1995. Assessing effects of agriculture on terrestrial wildlife: developing a hierarchical approach for the U.S. EPA. Landscape and Urban Planning 31: 99-115. 
Freemark K. and Smith J. 1995. A landscape retrospective for Walnut Creek, Story County. Technical report to the U.S. EPA. Unpublished contract report.

Hatfield J.L., Jaynes D.B., Burkart M.R., Cambardella C.A., Mooreman T.B., Prueger J.H., Smith M.A. 1999. Water Quality in Walnut Creek Watershed: Setting and Farming Practices. Journal of Environmental Quality 28: 11-24.

Klopatek J.M., Olson R.J., Emerson C.J. and Joness J.L. 1979. Land-use conflicts with natural vegetation in the United States. Environmental Conservation 6: 191-199.

Krebs J.R., Wilson J.D., Bradbury R.B. and Siriwardena G.M. 1999. A second Silent Spring? Nature 400: 611-612.

Lamy F., Bolte J., Santelmann M. and Smith C. 2002. Development and evaluation of multiple-objective decision-making methods for watershed management planning. Journal of the American Water Resources Association 38: 517-529.

Levins R. 1966. The strategy of model building in population biology. American Scientist 54: 421-431.

Likens G.E., Bormann F.H., Pierce R.S., Eaton J.S. and Johnson N.M. 1977. Biogeochemistry of a forested ecosystem. SpringerVerlag, New York, New York, USA.

Matson P.A., Parton W.J., Power A.G. and Swift M.J. 1997. Agricultural intensification and ecosystem properties. Science 277: 504-508.

Mitsch W.J., Day J.W. Jr., Gilliam J.W., Groffman P.M., Hey D.L., Randall G.W. and Wang N. 2001. Reducing nitrogen loading to the Gulf of Mexico from the Mississippi River Basin: Strategies to counter a persistent ecological problem. Bioscience 51: 373388.

Nassauer J.I. and Corry R.C.. 1999. Rural Watersheds and Policy. http//:www.snre.umich.edu/nassauer/lab_index.html. Accessed 06/25/2003.

Nassauer J.I., Corry R.C. and Cruse R. 2002. The landscape in 2025:Alternative landscape future scenarios as a means to consider agricultural policy. Journal of Soil and Water Conservation 57(2): 44A-53A

Nassauer J. I. and Corry R.C. 2004. Using normative scenarios in landscape ecology. Landscape Ecology 19: this issue.

Peterson G., Cumming A., Carpenter S. 2003. Scenario planning: a tool for conservation in an uncertain world. Conservation Biology 17(2): 358-366.

Pressey R.L., Humphries C.J., Margules C.R., Vane-Right R.I. and Williams P.H. 1993. Beyond opportunism: key principles for systematic reserve selection. Trends in Ecology and Evolution 8: $124-128$.

Prior J. 1991. Landforms of Iowa. University of Iowa Press, Iowa City, Iowa, USA.

Puckett L.J. 1994. Nonpoint and point sources of nitrogen in major watersheds of the United States. U.S. Geological Survey, Water Resources Investigations Report 94-4001, USGS Washington DC, USA.

Rabb G.B. and Sullivan T.B. 1995. Coordinating conservation: global networking for species survival. Conservation and Biodiversity 4: 536-543.

Robinson C.A., Cruse R.M. and Ghaffarzadeh M. 1996. Cropping system and nitrogen effects on mollison organic carbon. Soil Science Society of America Journal 60: 264-269.

Rosenzweig M.L. 1997. Heeding the warning in biodiversity's basic law. Science 284: 276-277.

Rustigian H. 1999. Assessing the potential impacts of alternative landscape designs on amphibian population dynamics. Master of
Science Research Paper, Department of Geosciences, Geography Program, Oregon State University, Corvallis, Oregon, USA.

Rustigian H., Santelmann M. and Schumaker N. 2003. Assessing the potential impacts of alternative landscape designs on amphibian population dynamics. Landscape Ecology 18: 65-81.

Sala O.E., Stuart Chapin III F., Armesto J.J., Berlow E., Bloomfield J., Dirzo R., Huber-Sanwald E., Huenneke L., Jackson R.B., Kinzig A., Leemans R., Dodge D.M., Mooney H.A., Oesterheld M., Poff N.L., Sykes M.T., Walker B.H., Walker M. and Wall D.H. 2000. Global biodiversity scenarios for the year 2100. Science 287: 1770-1774.

Santelmann M., Freemark K., White D., Nassauer J., Clark M., Danielson B., Eilers J., Cruse R., Galatowitsch S., Polasky S., Vaché K., Wu J. 2001. Applying Ecological Principles to LandUse Decision Making in Agricultural Watersheds. In: Dale V. and Haeuber R. (eds), Applying Ecological Principles to Land Management. Springer-Verlag, New York, New York, USA.

Schilling K.E. and Thompson C.A. 2000. Walnut Creek monitoring project, Iowa: Monitoring water quality in response to prairie restoration. Journal of the American Water Resources Association 36: 1101-1114.

Schoup M. 1999. Agricultural Runoff of Nutrients and Indicator Organisms in Buck Creek, Iowa. Masters of Science Thesis, Department of Civil and Environmental Engineering, University of Iowa, Iowa City, Iowa, USA.

Starfield A. 1997. A pragmatic approach to modeling for wildlife management. Journal of Wildlife Management 61: 261-270.

Steinitz C., Arias H., Bassett S., Flaxman M., Goode T., Maddock III T., Mouat D., Peiser R. and Shearer A.. 2003. Alternative futures for changing landscapes: The Upper San Pedro River Basin in Arizona and Sonora. Island Press, Washington DC, USA.

Tress B. and Tress G.. 2003. Scenario visualization for participatory landscape planning- a study from Denmark. Landscape and Urban Planning 64: 161-178.

US Census Bureau. 2001. Statistical Abstract of the United States: 2001. U.S. Department of Commerce, Washington, DC, USA.

US GAO. 1999. Report on Animal Agriculture: Waste Management Practices. U.S. General Accounting Office Report GAO/RCED99-205.

US OTA. 1995. Targeting environmental priorities in agriculture: Reforming program strategies. Congress of the United States, Office of Technology Assessment. OTA-ENV-640. Government Printing Office, Washington DC, USA.

USFWS-GAP. 2003. http://www.gap.uidaho.edu/ Accessed September 23, 2003.

USDA-NASS. 1999. Farms and Land in Farms 1993-1997, U. S. Department of Agriculture Statistical Bulletin 955.

USDA-NRCS. 1996. A Geography of Hope, USDA-Natural Resources Conservation Service. 80 pp.

USDA-NRCS. 1997. The PLANTS Database, Version 3.5 (http://plants.usda.gov). National Plant Data Center, Baton Rouge, LA 70874-4490 USA. Accessed September 12, 1997.

Vaché K., Eilers J. and Santelmann M.V. 2002. Water Quality Modeling for Evaluation of Alternative Agricultural Practices in Two Iowa Watersheds. Journal of the American Water Resources Association 38: 773-787.

Vitousek P.M., Mooney H.A., Lubchenco J., Melillo J.M.. 1997a. Human domination of earth's ecosystems. Science 277: 494499.

Vitousek P.M., Aber J.D., Howarth R.W., Likens G.E., Matson P.A., Schindler D.W., Schlesinger W.H., Tilman D.G. 1997 b. 
Human alteration of the global nitrogen cycle: sources and consequences. Ecological Applications 7: 737-750.

White D., Minotti P.G., Barczak M.J., Sifneos J.C., Freemark K.E., Santelmann M., Steinitz C.F., Keister A.R. and Preston E.M. 1997. Assessing risks to biodiversity from future landscape change. Conservation Biology 11: 349-360.

White D., Preston E.M., Freemark K.E. and Kiester A.R.. 1999. A hierarchical framework for conserving biodiversity. In: Klopatek
J.M. and Gardner R.H. (eds), Landscape Ecological Analysis: Issues and Applications. Springer, New York, New York, USA, pp. 127-153.

Williams J.R., Jones C.A. and Dyke P.T. 1988. EPIC, the Erosion Productivity Index Calculator, Model Documentation Vol. 1 USDA ARS, Temple, Texas, USA. 